\title{
Influence of rare earth elements on the structure and properties of powders based on zirconium dioxide during consolidation
}

\author{
Svetlana A. Oglezneva*, Maxim N. Kachenyuk, Andrey A. Smetkin and Valentina B. \\ Kul'met'eva
}

Perm National Polytechnic University, 614990, Perm, Russia

\begin{abstract}
Zirconium oxide powders with different contents of REE concentrate $(\mathrm{La}, \mathrm{Nd}, \mathrm{Pr})$ in an amount from 25 to $35 \mathrm{~mol}$. \% were synthesized by the method of reverse chemical deposition. The effect of the annealing temperature in the range of $600-1200{ }^{\circ} \mathrm{C}$ on the phase transformations of the synthesized powders has been investigated by Raman spectroscopy. It was found that the formation of REE zirconates with a pyrochlore structure occurs after annealing at a temperature of 1000 ${ }^{\circ} \mathrm{C}$. At higher annealing temperatures, the presence of tetragonal $\mathrm{ZrO}_{2}$ was noted in the samples with a lower concentrate content in the phase composition. A study of the influence of the sintering temperature of 1400$1600{ }^{\circ} \mathrm{C}$ on the densification processes, phase composition and microstructure of ceramic materials based on REE zirconates has been carried out. It has been shown that the densification processes proceed most slowly in a ceramic material with $35 \mathrm{~mol} \%$ of rare-earth oxides, and at all sintering temperatures it has a stable phase composition, consisting mainly of rare-earth zirconates with a pyrochlore structure.
\end{abstract}

\section{Introduction}

In recent years, considerable attention has been paid to zirconates of rare earth elements (REE) with the general formula $\mathrm{Ln}_{2} \mathrm{Zr}_{2} \mathrm{O}_{7}$, which crystallize in pyrochlore and fluorite structures and have high melting points. Due to a number of properties, these compounds are used as new solid electrolytes with high oxygen-ionic conductivity in a hightemperature fuel cell, exhibit dielectric, piezoelectric or ferroelectric, as well as fluorescent and phosphoric properties, can be used as materials for electronic technology, as well as catalysts. REE zirconates have chemical and radiation resistance, high capacity with respect to radionuclides and are considered promising for immobilization of high-level nuclear waste. It should be noted that they are promising as materials for thermal barrier coatings for refractory materials due to their high melting point, thermal stability and chemical resistance, low thermal conductivity and good resistance to sintering at operating temperatures up to $1300-1400^{\circ} \mathrm{C}[1-5]$.

*Correspondingauthor:svetlana.iron@yandex.ru 
The aim of the work was to study the process of formation of ceramic materials based on zirconates using a REE concentrate.

\section{Materials and research methods}

Powders for the synthesis of zirconates were obtained by the method of reverse coprecipitation from a freshly prepared $0.5 \mathrm{M}$ aqueous solution of $\mathrm{ZrOCl}_{2} \cdot 8 \mathrm{H}_{2} \mathrm{O}$ salt of pure grade. As a source of rare earth elements, we used a rare earth element concentrate in the form of carbonates produced by JSC Solikamsk Magnesium Plant (Perm Territory, Russia) in which it was (wt.\%): $\mathrm{La}_{2} \mathrm{O}_{3}-61,2 ; \mathrm{Nd}_{2} \mathrm{O}_{3}-25,5 ; \operatorname{Pr}_{6} \mathrm{O}_{11}-10,3 ; \mathrm{CeO}_{2}-$ 0,$0065 ; \mathrm{Nb}_{2} \mathrm{O}_{5}-0,09 ; \mathrm{CaO}-0,67 ; \mathrm{SrO}-0,05 ; \mathrm{Fe}_{2} \mathrm{O}_{3}-0,02 ; \mathrm{TiO}_{2}-0,10$. The content of REE oxides, calculated from the phase diagram of $\mathrm{ZrO}_{2}-\mathrm{La}_{2} \mathrm{O}_{3}$, varied in amounts of 25 , 30 , and $35 \mathrm{~mol} \%$.

The REE concentrate was dissolved in concentrated $\mathrm{HNO}_{3}$ with heating. Coprecipitation was carried out while maintaining the $\mathrm{pH}$ of the reaction medium equal to 9. A $25 \%$ aqueous ammonia solution was used as a precipitant. The resulting gel-like precipitate was washed to remove $\mathrm{Cl}^{-}$and $\mathrm{NH}^{+}{ }_{4}$ ions with distilled water using vacuum filtration. The precipitate dried in air at a temperature of $50{ }^{\circ} \mathrm{C}$ was ground in a SAND planetary mill at a rotation speed of $160 \mathrm{rpm}$ for 1 hour in an ethyl alcohol medium at a weight ratio of powder, grinding bodies and alcohol of 1: $2: 1$. Heat treatment of pre-ground powders was carried out in the temperature range from 600 to $1200{ }^{\circ} \mathrm{C}$ in a muffle furnace with isothermal holding for $60 \mathrm{~min}$ in air.

The phase composition of the samples was studied by Raman spectroscopy. Raman spectra were obtained on a SENTERRA multifunctional Raman spectrometer (Bruker, Germany) at an emitting laser wavelength of $532 \mathrm{~nm}$.

The samples were pressed on a hydraulic press by cold uniaxial pressing at a specific pressing pressure of $150 \mathrm{MPa}$. A 4\% aqueous solution of polyvinyl alcohol grade PVA 7/2 GOST 10779-69 in an amount of $10 \%$ by weight of the powder was used as a temporary technological binder. The samples were sintered in high-temperature electric resistance furnaces VTP 06M1 and NT 64/17 (Nabertherm GmbH, Germany) in the temperature range $1400-1600{ }^{\circ} \mathrm{C}$ with exposure for $2 \mathrm{~h}$ in air.

The apparent density and open porosity were determined by the hydrostatic method according to GOST 473.4-81. The microstructural analysis of the sintered samples was carried out by atomic force microscopy in a semicontact mode using a Solver Next scanning probe microscope (NT-MDT, Russia) on thin sections after high-temperature etching at a temperature of $100-150{ }^{\circ} \mathrm{C}$ below the sintering temperature in air.

\section{Experimental results and discussion of studies}

Using the method of Raman spectroscopy, the effect of heat treatment in the temperature range $600-1200{ }^{\circ} \mathrm{C}$ on the phase composition of the powder depending on the content of REE oxides was studied (Fig. 1). It was found that after annealing at a temperature of 600 ${ }^{\circ} \mathrm{C}$, all powders are in an amorphous state, since the spectrum has no pronounced peaks. An increase in temperature to $800^{\circ} \mathrm{C}$ leads to the formation of cubic $\mathrm{ZrO}_{2}\left(617 \mathrm{~cm}^{-1}\right)$, which is characterized by the presence of an amorphous-like spectrum with a broad peak in the range $600-625 \mathrm{~cm}^{-1}$ [6]. A broad low intensity peak at $340 \mathrm{~cm}^{-1}$ can be attributed to the only active Raman mode of zirconate with a disordered fluorite structure (Fig. 1a) [7]. 


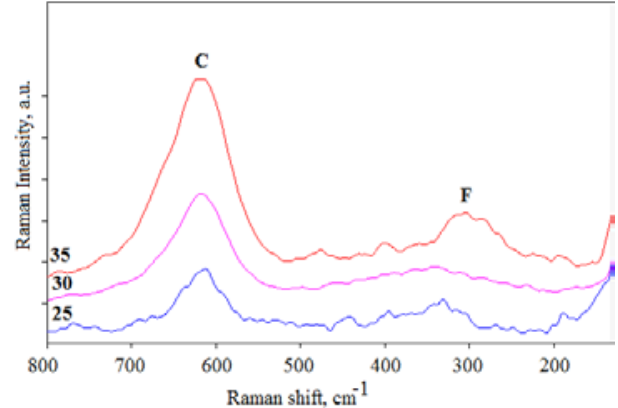

a

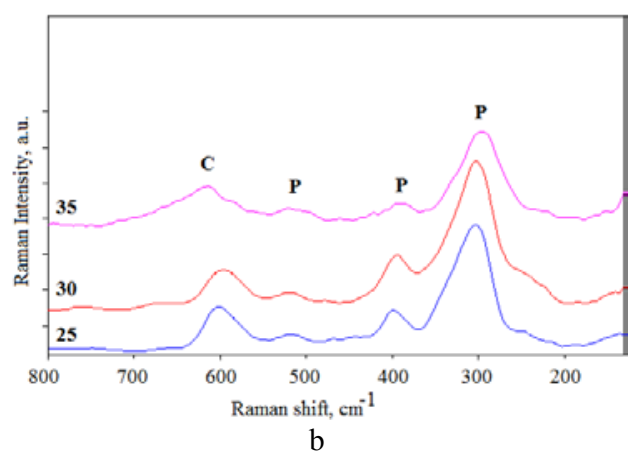

b

Fig. 1. Raman spectra of synthesized powders with different contents of REE concentrate after annealing at temperatures: $\mathrm{a}-800, \mathrm{~b}-1000^{\circ} \mathrm{C}$. c - cubic $\mathrm{ZrO}_{2}$; R - pyrochlore; F - fluorite.

After annealing at $1000{ }^{\circ} \mathrm{C}$, lines appeared in the spectrum corresponding to zirconates with a pyrochlore structure (Fig. 1.b). The Raman spectra of compounds of the $\mathrm{A}_{2} \mathrm{~B}_{2} \mathrm{O}_{7}$ type with a pyrochlore structure are characterized by the presence of six active modes, of which the main ones are $300 \mathrm{~cm}^{-1}(\mathrm{Eg}), 395 \mathrm{~cm}^{-1}$ (F2g), $492 \mathrm{~cm}^{-1}$ (A1g), $516 \mathrm{~cm}^{-1}$ (F2g ) [810]. The line with the highest intensity is $\sim 300 \mathrm{~cm}^{-1}$. There also appears to be a small amount of zirconium oxide as the spectrum shows a line at $\sim 615 \mathrm{~cm}^{-1}$. A further increase in the annealing temperature to $1200{ }^{\circ} \mathrm{C}$ leads to a narrowing of the main peak of zirconates $\left(300 \mathrm{~cm}^{-1}\right)$, which indicates the formation of a more perfect crystal structure. The spectrum also shows the strongest lines corresponding to tetragonal zirconium dioxide $(150,265,644$ $\mathrm{cm}^{-1}$ ), the intensity of which decreases with increasing concentrate content.

The effect of the sintering temperature on the compaction processes, phase composition and microstructure of ceramic materials based on REE zirconates has been studied.

The apparent density of the samples after molding was $2.91-3.15 \mathrm{~g} / \mathrm{cm}^{3}$. After sintering at a temperature of $1400{ }^{\circ} \mathrm{C}$, the density of all specimens is rather low, open porosity is $35-$ $40 \%$ (Fig. 2).

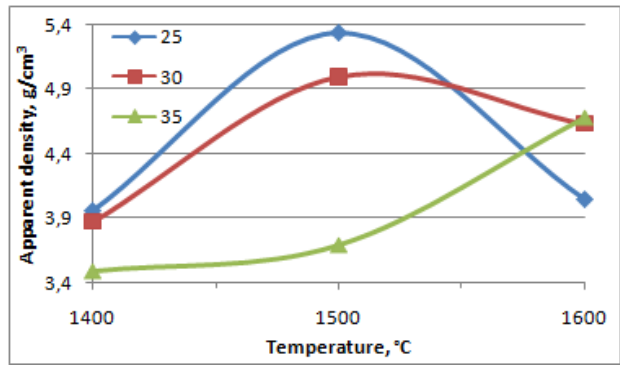

a

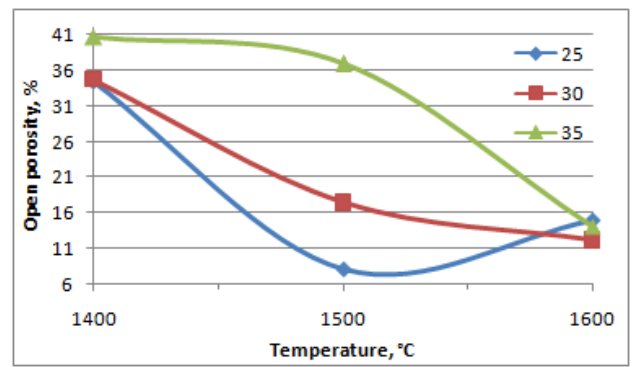

b

Fig. 2. Dependences of the apparent density (a) and open porosity (b) of ceramics based on rare-earth zirconates on the sintering temperature.

Although the volumetric shrinkage of samples with 25 mol.\% REE is quite large, up to $31 \%$, an increase in the sintering temperature to $1500{ }^{\circ} \mathrm{C}$ led to a significant decrease in open porosity: more than 4 times for ceramics with 25 mol.\% REE oxides and 2 times for ceramics with 30 mol.\% REE oxides. In this case, the apparent density of these ceramics has a maximum value. The density of ceramics with 35 mol.\% of REE reaches the highest value only after sintering at $1600{ }^{\circ} \mathrm{C}$; open porosity is $12-15 \%$. At the same time, for ceramics with a lower content of REE oxides, a decrease in the apparent density and volumetric shrinkage was noted. 
The analysis carried out by Raman spectroscopy showed that after sintering at $1400^{\circ} \mathrm{C}$, the phase composition of all samples, except for zirconates of rare-earth elements with a pyrochlore structure, contains tetragonal $\mathrm{ZrO}_{2}$, the amount of which decreases with an increase in the content of rare-earth oxides (Fig. 3 a).

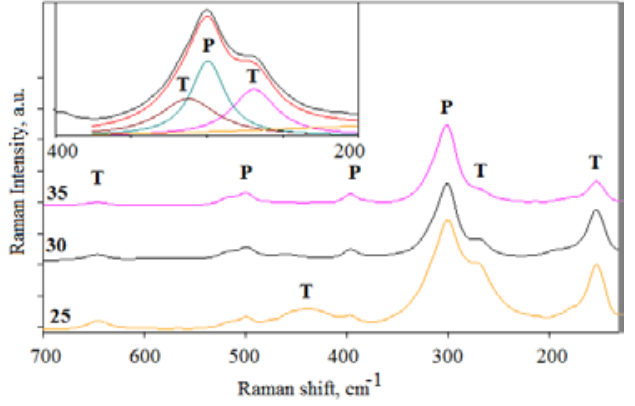

a

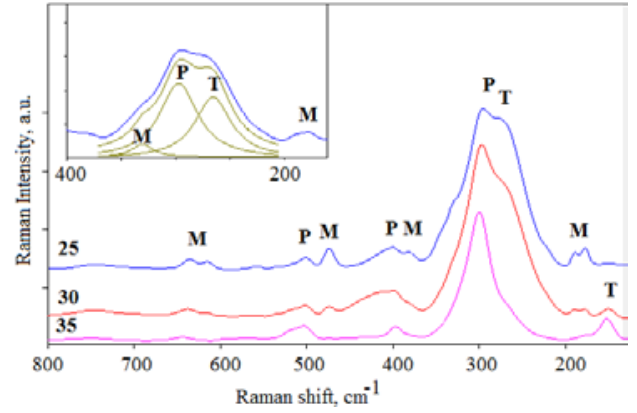

$\mathrm{b}$

Fig. 3. Raman spectra of ceramics with different contents of REE oxides after sintering at $1400{ }^{\circ} \mathrm{C}$ (a) and $1600{ }^{\circ} \mathrm{C}: \mathrm{M}$ - monoclinic $\mathrm{ZrO}_{2}, \mathrm{~T}$ - tetragonal $\mathrm{ZrO}_{2}, \mathrm{P}$ - pyrochlore. Inset: decomposition of the $295 \mathrm{~cm}^{-1}$ line of the Raman spectrum of the sample with 25 mol.\% REE.

With an increase in the sintering temperature to $1500{ }^{\circ} \mathrm{C}$, in the Raman spectra of ceramics with 25 and 30 mol.\% of rare-earth oxides, lines (178 and $190 \mathrm{~cm} \mathrm{-} \mathrm{1)} \mathrm{appear,}$ corresponding to monoclinic $\mathrm{ZrO}_{2}$. The Raman spectrum of ceramics with 35 mol.\% REE oxides remained unchanged; the phase composition consists almost entirely of zirconate with a pyrochlore structure with an insignificant amount of tetragonal zirconium dioxide. After sintering at a temperature of $1600{ }^{\circ} \mathrm{C}$ in ceramics with 25 and $30 \mathrm{~mol} . \%$ of rare-earth oxides, the amount of monoclinic $\mathrm{ZrO}_{2}$ increases, because the intensity of the lines at 178 and $190 \mathrm{~cm}^{-1}$ increases, and other lines corresponding to it appear in the spectrum (Fig. 3 b). An increase in the amount of monoclinic $\mathrm{ZrO}_{2}$ in the phase composition is associated with a decrease in the apparent density of ceramics from 25 and 30 mol.\% REE. The phase composition of ceramics with 35 mol.\% of rare-earth oxides remains unchanged.

According to microstructural analysis data after sintering at 1500 and $1600{ }^{\circ} \mathrm{C}$, the microstructure of all samples consists of polyhedral grains, the size of which depends on the content of REE oxides and the sintering temperature (Fig. 4).

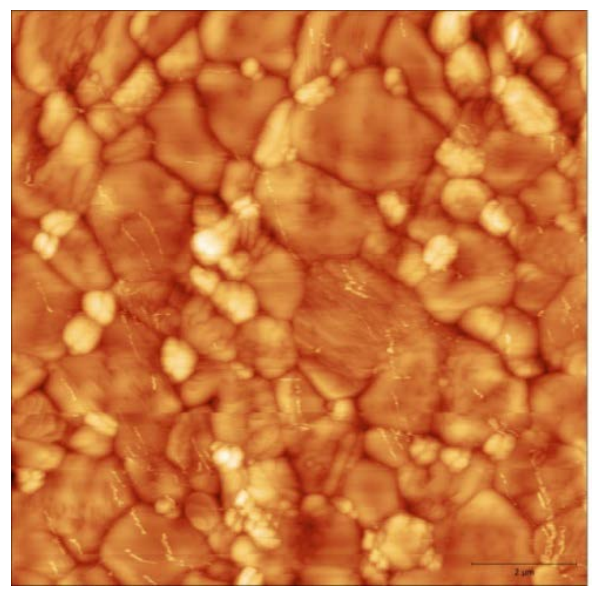

a

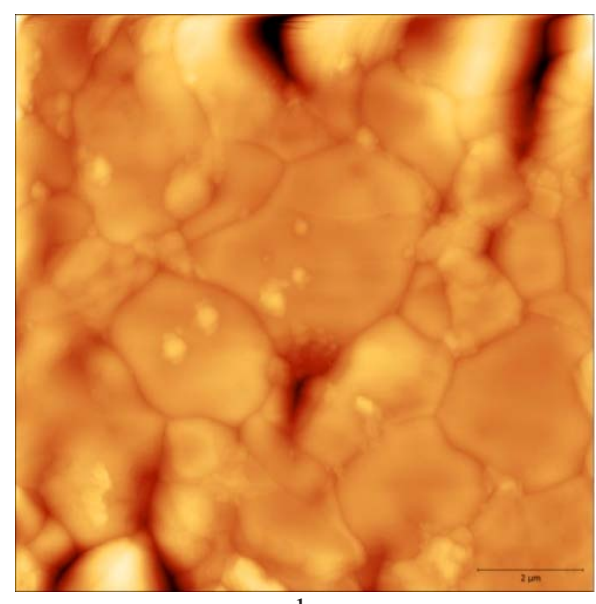

b

Fig. 4. AFM image of the microstructure of ceramics based on zirconates with $30 \mathrm{~mol} \%$ REE after sintering at a temperature of: $\mathrm{a}-1500^{\circ} \mathrm{C} ; \mathrm{b}-1600^{\circ} \mathrm{C}$. Scanning area $11 \times 11 \mu \mathrm{m}$. 
In ceramics with 25 and 30 mol.\% of rare-earth oxides, the microstructure contains both coarse grains up to $2 \mu \mathrm{m}$ in size and dispersed precipitates, the size of which does not exceed $0.3 \mu \mathrm{m}$, which is apparently associated with the formation of zirconium dioxide. The microstructure of ceramics with $35 \mathrm{~mol} \%$ of rare-earth oxides consists of agglomerates of grains with an average size of $0.38 \mu \mathrm{m}$, there are practically no dispersed precipitates. An increase in the sintering temperature leads to a significant increase in the grain of the ceramics, regardless of the content of rare-earth oxides, but the smallest grain size is in ceramics with $35 \mathrm{~mol} \%$ of rare-earth oxides.

The effect of isothermal holding in air at a temperature of $1300{ }^{\circ} \mathrm{C}$ for $10 \mathrm{~h}$ on the phase composition of ceramics has been studied. Analysis by Raman spectroscopy showed that the phase composition of the samples remained virtually unchanged (Fig. 5).

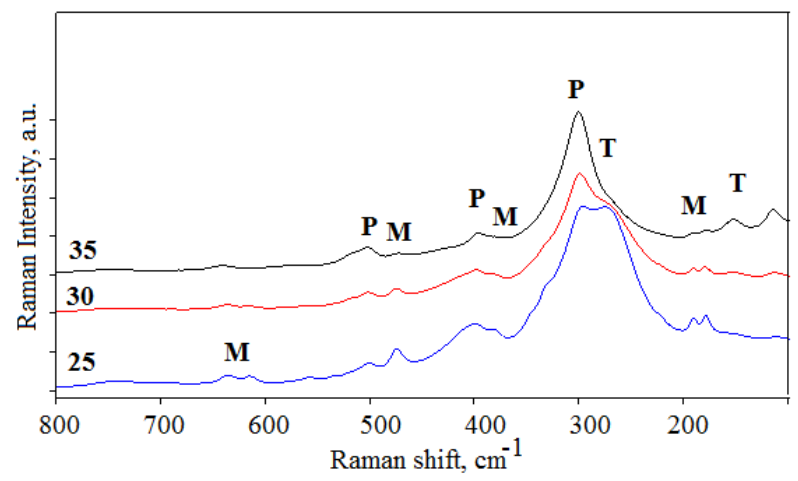

Fig. 5. Raman spectra of ceramics with different contents of REE oxides after isothermal exposure in air at $1300{ }^{\circ} \mathrm{C}$ for $10 \mathrm{~h}: \mathrm{M}$ - monoclinic $\mathrm{ZrO}_{2}, \mathrm{~T}$ - tetragonal $\mathrm{ZrO}_{2}, \mathrm{P}$ - pyrochlore.

The formation of the pyrochlore structure in ceramics already at $1000{ }^{\circ} \mathrm{C}$ made it possible to successfully use the investigated compositions to create a heat-protective coating wiht minimal porosity on the Inconel 625 powder alloy by the SPS method at a temperature of $1050{ }^{\circ} \mathrm{C}$ (Fig. 6).

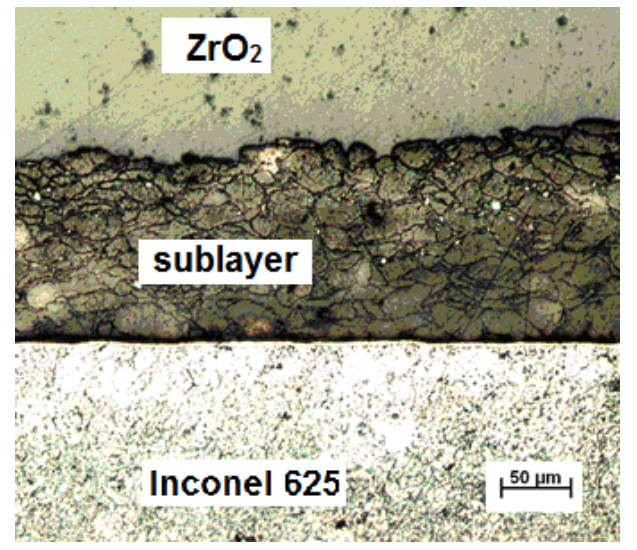

Fig. 6. Gradient material structure «Inconel 625 - Ceramics based on zirconates ».

\section{Conclusion}

Powders based on zirconium oxide with different concentrations of REE concentrate were synthesized by the method of reverse chemical deposition. It was found that the formation 
of REE zirconates with a pyrochlore structure occurs after annealing at a temperature of $1000{ }^{\circ} \mathrm{C}$. At higher annealing temperatures, the presence of tetragonal $\mathrm{ZrO}_{2}$ was noted in the samples with a lower concentrate content in the phase composition. It is shown that, during sintering, the densification processes of single-phase ceramics, consisting of zirconates with a pyrochlore structure, proceed more slowly, and at all sintering temperatures it has a stable phase composition. The ceramic microstructure after sintering consists of polyhedral grains, the size of which increases with an increase in the sintering temperature. The resulting ceramic material based on REE zirconates has phase stability at $1300^{\circ} \mathrm{C}$.

The study of the reduction of the sublayer with the outer ceramic layer was carried out within the framework of the state assignment of the Ministry of Education and Science of Russia to carry out fundamental scientific research (Topic "Development of theoretical and technological foundations and digital technologies for the design of functional composite materials, multifunctional nanocoatings and diagnostic information systems for monitoring highly loaded elements of aircraft structures", No. FSNM -2020-0026).

The reported study of formation of ceramic lay was funded by RFBR and Perm Territory according to the research project № 19-48-590007.

\section{References}

1. J. Feng, B. Xiao, C.L. Wan, Z.X. Qu , Z.C. Huang, J.C. Chen, R. Zhou, W. Pan, Acta Materialia. 59, 1742 (2011)

2. A.V. Shlyakhtina, L.G.Shcherbakova, Russian Journal of Electrochemistry. 48, 1 (2017)

3. Y. Tong, L. Lu, X. Yang, X. Wang, Solid State Sciences. 10, 1379 (2008).

4. J. Zhang, X. Guo, Y.-G. Jung, L. Li, J. Knapp, Surf. Coat. Technol. 323, 18 (2017)

5. X. Cao, J. Mater. Sci. Technol. 23, 15 (2007)

6. S. N. Basahel., T. T. Ali, M. Mokhtar, K. Narasimharao, Nanoscale Research Letters. 10, 73 (2015)

7. B. Paul, K. Singh, T. Jaroń, A. Roy, A. Chowdhury, J. Alloys Compd. 686, 130 (2016)

8. L. Guo, Y. Zhang, F. Ye, J. Am. Ceram. Soc. 98, 1013 (2015)

9. Z. Xu, L. He, X. Zhong, J. Zhang, X. Chen, H. Ma, X. Cao, Journal of Alloys and Compounds. 480, 220 (2009)

10. C. Wang, Y. Wang, Y. Cheng, W. Huang, Z.S. Khan, X. Fan, Y. Wang, B. Zou, X. Cao, Mater Sci. 47, 4392 (2012) 